\title{
A Study on the Reentry Motivation Types of the Young Chinese Migrant Workers Returning from South Korea
}

\author{
CHENG Jing ${ }^{1, a}$, ZHU Kun ${ }^{1, b}$, \\ ${ }^{1}$ Changchun Normal University, China \\ Achengjing1981@hotmail.com, b9438832@qq.com \\ Corresponding author:ZHU Kun
}

Keywords: reentry motivation,young Chinese migrant workers, South Korea,

\begin{abstract}
This paper explains and demonstrates reentry motivations of the Chinese migrant laborer returning from South Korea. Qualitative and Quantitative analytical method are used in this paper. 500 questionnaires were distributed out and 465 valid pieces were collected. Through the analysis, it is found that there are two major returning types: initiative return type(conservative,resting and innovative return) and passive return type(not adaptable,unfavorable policy return). A specific returning type could result in different return period. The return motivations could be influenced by diversified factors, such as:experience, gender, family and ethnicity.
\end{abstract}

\section{Introduction}

This research is conducted in Yanbian Korean Autonomous Prefecture（Yanbian hereafter) in Jilin Province. As the only Korean Autonomous Prefecture, Yanbian is an adjacent to the border areas of China, Russia and Korea Peninsula. Yanbian, as a pioneer, started its labor export industry to South Korea under this social economic situation. Yanbian got great economic benefits through labor export, yet it faces various social,economic, security problems. In order to keep a sustainable,safe and prosperous development, Yanbian needs to explore its labor forces to cope with the labor deficiency challenges. The young cross-border migrant laborers have great potential to empower labor force of the local community. Therefore, this paper aims at analyzing the returning types of the Chinese migrant laborers returning from South Korea from the perspective of time dimension.

\section{Methodology}

\subsection{Data sources}

\subsubsection{Primary data}

The primary data was collected by sending questionnaires and doing a preliminary investigation. The preliminary investigation were made through interviews to figure out the major reentry motivations.questionnaires were distributed after the qualitative research. The respondents are young migrant workers aged between 18-40 in 8 cities in Yanbian Prefecture. The questionnaire was issued and recovered from February 2015 to March 2016. A total of 500 questionnaires were distributed and 465 valid questionnaires were returned, including 232 Chaoxianzu(Korean Chinese) ethic respondents, 231 Han respondents, and 2 other ethnics.

\subsubsection{Secondary data}

Secondary data were collected through books, reports and the information from mass media.

\subsection{Analytical method}

This paper integrates both qualitative and quantitative analytical method. Qualitative method is used to analyze the major reentry motivations, quantitative analysis is used to prove the reentry motivation hypothesis and the characteristics of different types. 


\subsection{Theoretical basis}

The theoretical basis of this article is Francesco Cerase's study of four types of return from the perspective of ideals, expectations, and needs for returning home, he proposed four types of return: return of failure, return of conservatism, and return of retirement and return of innovation. Based on the research object and the actual needs of the research, the type of returning home for Chinese young migrant workers returning from South Korea are divided into 2 major types: initiative reentry and and passive reentry.

\section{Findings}

\subsection{Initiative Reentry}

\subsubsection{Return of Conservatism}

The conservative returning type means that returnees set a good goal for working abroad and for return. Once the goal can be achieved, immigrants will return home and plan to settle down permanently.

Table 1. Proportion of Major Ethnic Groups in the Return Type of Conservatism(Unit: person, \%)

\begin{tabular}{c|c|c|c|c|c|c|c|c}
\hline \multirow{2}{*}{ Return type } & \multicolumn{2}{|c|}{$\begin{array}{c}\text { Chaozianzu } \\
\text { ethic }\end{array}$} & \multicolumn{2}{|c|}{ Han } & \multicolumn{2}{c|}{ other } & \multicolumn{2}{c}{ Total } \\
\cline { 2 - 8 } & Pop. & pct & Pop. & pct & Pop. & pct & Pop. & pct \\
\hline $\begin{array}{c}\text { Conservative } \\
\text { type }\end{array}$ & 4 & $5 \%$ & 80 & $95 \%$ & 0 & 0 & 75 & $18 \%$ \\
\hline
\end{tabular}

(data source: result of questionnaire analysis)

According to statistics, the proportion of the Han nationality in the conservative returning population is much higher than that of the Chaoxianzu returnees. As shown in Table 2, Han conservative returnees account for $95 \%$ of the conservative returnees, and Koreans only account for $5 \%$ of the total. From this data, it can be seen that the majority of Chaoxianzu laborers international work activities in South Korea are not short-term and single-time economic flows, but are continuous cross-border flows.

\subsubsection{Return of Resting}

Return of resting is a returning type based on Cerase's return of retirement. Many immigrants have returned to China after earning some money abroad, and have returned to their hometowns for the purpose of nursing and even enjoyment. After returning home, these returnees do not rush to find a job or start a business, but are completely in a short-term "retirement" state. When the money they earned from abroad was spent out, they will once again work abroad to make money.

Table 2. Proportion of ethnic groups in the Return Type of Resting(Unit: person, \%)

\begin{tabular}{c|c|c|c|c|c|c|c|c}
\hline \multirow{2}{*}{$\begin{array}{c}\text { Return } \\
\text { type }\end{array}$} & \multicolumn{2}{|c|}{ Chaoxianzu } & \multicolumn{2}{c|}{ Han } & \multicolumn{2}{c|}{ other } & \multicolumn{2}{c}{ Total } \\
\cline { 2 - 8 } & Pop. & pct & Pop. & pct & Pop. & pct & Pop. & pct \\
\hline $\begin{array}{c}\text { Return of } \\
\text { resting }\end{array}$ & 158 & $67 \%$ & 78 & $32 \%$ & 1 & $1 \%$ & 237 & $51 \%$ \\
\hline
\end{tabular}

(data source: result of questionnaire analysis)

As shown in Table 3, Chaoxianzu returnees account for $67 \%$ of the returnee population. First of all, it originated from the preferential cross-border policies issued by Korea for Korean ethnicity. 
Secondly, high income enables the returnees to rest back in China. There are relatively few groups of Han people returning to their hometowns, accounting for $32 \%$ of the total number of people who return home for recuperation.

\subsubsection{Return of Innovation}

The return of innovation refers to the returnee' efforts to, accumulate certain economic, cultural, and social capital. After returning home, they use these capitals to better live, work, or start a business.

Table 3. Proportion of major ethnic groups in the Return Type of Innovation(Unit: person, \%)

\begin{tabular}{c|c|c|c|c|c|c|c|c}
\hline \multirow{2}{*}{$\begin{array}{c}\text { Return } \\
\text { type }\end{array}$} & \multicolumn{2}{|c|}{ Chaoxianzu } & \multicolumn{2}{|c|}{ Han } & \multicolumn{2}{c|}{ other } & \multicolumn{2}{c}{ Total } \\
\cline { 2 - 9 } & Pop. & pct & Pop. & pct & Pop. & pct & Pop. & pct \\
\hline $\begin{array}{c}\text { innovative } \\
\text { return }\end{array}$ & 42 & $52 \%$ & 39 & $48 \%$ & 0 & 0 & 81 & $17 \%$ \\
\hline
\end{tabular}

(data source: result of questionnaire analysis)

As shown in Table 4, Chaoxianzu are slightly higher than the other ethnic groups in terms of innovative return. The main reason is language and cultural advantages. Entrepreneurship is another important factor. Due to the slow economic development in Yanbian area and the incomplete economic structure, the related supporting policies are still very limited. The entrepreneurial returnees usually accumulate a large amount of manpower, economic and social capital before return.

\subsection{Passive Return}

\subsubsection{Return of Failure}

Return of failure refers to the returnee who was forced to return to China because he was unable to adapt to a foreign life during his stay abroad. There are various reasons why returnees cannot adapt to life abroad, such as discrimination or unfair treatment, conflicting cultural values, stereotypes, lifestyle, interpersonal relationships or work difficulties.

Table 4. Population Percentage of ethnic groups in the short-term Return Type(Unit: person, \%)

\begin{tabular}{c|c|c|c|c|c|c|c|c}
\hline \multirow{2}{*}{$\begin{array}{c}\text { Return } \\
\text { type }\end{array}$} & \multicolumn{2}{|c|}{ Chaoxianzu } & \multicolumn{2}{c|}{ Han } & \multicolumn{2}{c|}{ other } & \multicolumn{2}{c}{ Total } \\
\cline { 2 - 8 } & Pop. & pct & Pop. & pct & Pop. & pct & Pop. & pct \\
\hline $\begin{array}{c}\text { Return of } \\
\text { failure }\end{array}$ & 2 & $23 \%$ & 4 & $67 \%$ & 0 & 0 & 4 & $1 \%$ \\
\hline
\end{tabular}

(data source: result of questionnaire analysis)

As shown in Table 4, the percentage of Han is slightly higher than Chaoxianzu in terms of the failure type. Cultural difference is not the major reason for the result,because the migrant workers of different ethnicity from Yanbian Korean Autonomous Prefecture have long been integrated culturally. The biggest challenge is the $3 \mathrm{D}$ (difficult, dirty and dangerous ) jobs that were done by the young Chinese migrant laborers in South Korea. Some laborers were forced to return due to the discomfort caused by the exhausting work.

\subsubsection{Return of Unfavorable Policy}

The return of unfavorable policy type refers to the returnees who had to repatriate because of visa issues or other unfavorable policies.migrant workers who have to be returned to China due to visas that have to be returned due to reasons such as illegal stay in Korea. Because most migrant workers payed big sum of commission fee to the job agencies, the return of this group is not voluntary but forced. The returnees usually face obstacles to social adaptation both domestic and abroad. 
Table 5. Proportion of major ethnic groups in the Return of Unfavorable Policies(Unit: person, \%)

\begin{tabular}{c|c|c|c|c|c|c|c|c}
\hline \multirow{2}{*}{$\begin{array}{c}\text { Return } \\
\text { type }\end{array}$} & \multicolumn{2}{|c|}{ Chaoxianzu } & \multicolumn{2}{c|}{ Han } & \multicolumn{2}{c|}{ other } & \multicolumn{2}{c}{ Total } \\
\cline { 2 - 8 } & Pop. & pct & Pop. & pct & Pop. & pct & Pop. & pct \\
\hline $\begin{array}{c}\text { Unfavorab } \\
\text { le policies }\end{array}$ & 26 & $27 \%$ & 78 & $62 \%$ & 1 & $1 \%$ & 98 & $23 \%$ \\
\hline
\end{tabular}

(data source: result of questionnaire analysis)

As shown in table 5, Han returnees accounts for $62 \%$, which shows significant contrast with Chaoxianzu of $27 \%$. South Korea introduced a preferential visa policy for Chaoxianzu in 2007. Although the introduction of this policy has its ethnic historical origins, it has virtually created inequality in visas, employment opportunities, and employment treatment. Chinese Han and other ethnic young migrant workers still need to spend a lot of agency fees, or have to become "black workers" or work for a few jobs in order to earn as much as Chaoxianzu workers in South Korea.

\section{Summary}

In general, the proportion of initiative returnees is higher than passive returnees, which are $76 \%$ and $24 \%$ respectively (see Table 6). By understanding the return motivations, the local government and society could develop favorable policies and attractive conditions to explore the return laborers.

Table 6. Reentry types from the perspective of motivation

\begin{tabular}{c|c|c|c|c|c|c}
\hline & \multicolumn{2}{|c|}{ Passive Return } & \multicolumn{2}{c|}{ Initiative Return } & \multirow{2}{*}{ total } \\
\cline { 2 - 6 } & $\begin{array}{c}\text { Culture } \\
\text { shock type }\end{array}$ & $\begin{array}{c}\text { Unfavorable } \\
\text { policy type }\end{array}$ & $\begin{array}{c}\text { Conservative } \\
\text { type }\end{array}$ & $\begin{array}{c}\text { holiday } \\
\text { type }\end{array}$ & $\begin{array}{c}\text { Innovation } \\
\text { type }\end{array}$ & \\
\hline Chaoxianzu & $1 \%$ & $11 \%$ & $2 \%$ & $68 \%$ & $18 \%$ & $100 \%$ \\
\hline Han & $1 \%$ & $34 \%$ & $35 \%$ & $13 \%$ & $17 \%$ & $100 \%$ \\
\hline Other ethnic & 0 & $50 \%$ & $50 \%$ & 0 & 0 & $100 \%$ \\
\hline \multirow{2}{*}{\begin{tabular}{c} 
Propoup \\
\cline { 2 - 7 }
\end{tabular}} & $1 \%$ & $23 \%$ & $18 \%$ & $51 \%$ & $17 \%$ & $100 \%$ \\
\cline { 2 - 6 } & \multicolumn{2}{|c|}{$24 \%$} & & $76 \%$ & & $100 \%$ \\
\hline
\end{tabular}

\section{Acknowledgement}

This research was financially supported by the Social Science Foundation of Jilin Province, "Collective Identity of the Chaoxianzu Ethnic Group in International Mobility" (Grant NO.2018B133).Meanwhile,this article is a phased achievement of the horizontal project of Jilin University, "Research on Big Data Collection of "Cultural Protection" in China" (Project No. 371182101401).

\section{References}

[1] Cheng Jing, A Study on Reentry Re-adaptation of the Young Chinese Migrant Laborers returning from South Korea,[D]Jilin University, 2017.

[2] Francesco P. Cerase. Expectations and Reality: A Case Study of Return Migration from the United States to Southern Italy, International Migration Review, 1974, 8(26) 